\title{
Evaluation of the population-level impact of the maternal health voucher program in Uganda
}

Reproductive Health Vouchers Evaluation Team

Follow this and additional works at: https://knowledgecommons.popcouncil.org/departments_sbsr-rh

Part of the Demography, Population, and Ecology Commons, International Public Health Commons, Maternal and Child Health Commons, and the Women's Health Commons How does access to this work benefit you? Let us know!

\section{Recommended Citation}

Reproductive Health Vouchers Evaluation Team. 2012. "Evaluation of the population-level impact of the maternal health voucher program in Uganda," Technical report. Nairobi: Population Council. 


\title{
Evaluation of the population-level impact of the maternal health voucher program in Uganda
}

\author{
Technical Report
}

Reproductive Health Vouchers Evaluation Team

Population Council

May 02, 2012 


\section{ACKNOWLEDGEMENTS}

The expanded reproductive health vouchers program in Uganda for maternal health services and treatment of sexually transmitted infections (STIs) was funded by the German Development Bank (KfW) and the Global Partnership on Output-based Aid (GPOBA-World Bank) with GPOBA subsidizing $97 \%$ of the vouchers. Marie Stopes International - Uganda (MSI$\mathrm{U}$ ) is the voucher management agency (VMA) whose role is to accredit providers, distribute the vouchers, ensure quality, verify and process claims, and control fraud. The implementation of the program is also supported by the Ministry of Health $(\mathrm{MOH})$ - Uganda.

GPOBA contracted Venture Strategies for Health and Development (VSHD) to undertake a population-based evaluation of the program in 2008. VSHD coordinated data collection activities in the population-based household surveys in 2008 and 2010-2011. The surveys were implemented in collaboration with MSI-U, Mbarara University of Science and Technology, Population Council, and the University of California at Berkeley. The Bill and Melinda Gates Foundation supported the analysis of the data and the writing of this report.

The successful implementation of the surveys was made possible by a team of Uganda-based research assistants. The Population Council Reproductive Health Vouchers Evaluation team based in Nairobi provided technical assistance during the implementation of the surveys and management and analysis of the data. The team comprised Francis Obare who conducted the analysis and drafted this report, Lucy Kanya, Jerry Okal, Timothy Abuya, Rebecca Njuki, Charlotte Warren, and Ben Bellows who was the Principal Investigator of the Uganda evaluation project.

The authors wish to acknowledge the individuals and organizations that made the evaluation project possible. These include: Dr. Edgar Mulogo and Dr. Fred Bagenda at the Department of Community Health, Mbarara University of Science and Technology; Dr. Peter Okwero at the World Bank's Africa Region's Human Development Department in Kampala, Leslie Villegas at the Global Partnership on Output-Based Aid (GPOBA, World Bank) in Washington DC; and Jon Cooper, Christine Namayanja, and the many dedicated individuals at MSI-U.

Ethical clearance for the surveys was obtained from the Institutional Review Boards of the Population Council and Mbarara University. 


\section{CONTENTS}

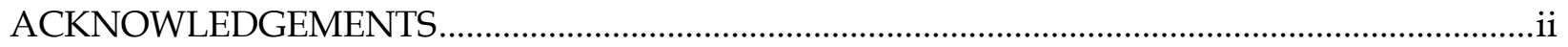

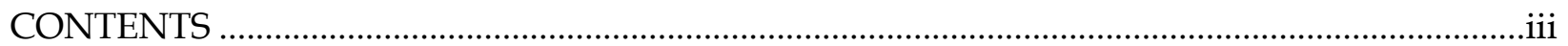

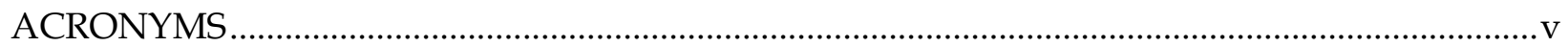

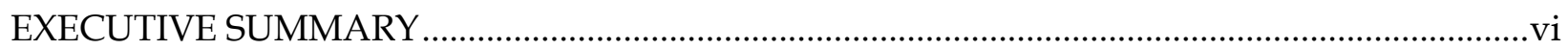

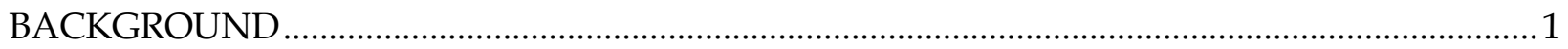

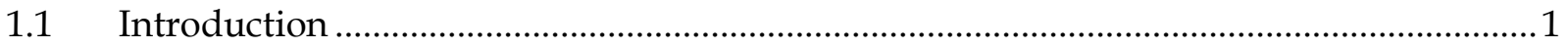

1.2 Examples of Reproductive Health Voucher Programs.................................................2

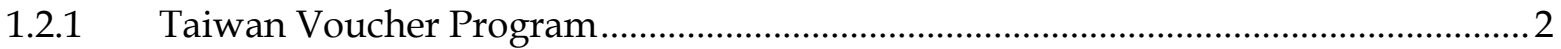

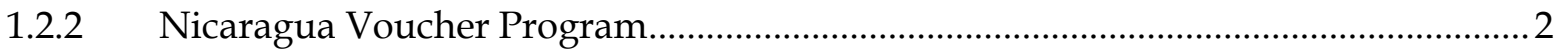

1.2.3 Gujarat Safe Delivery Voucher Program ................................................................. 2

1.2.4 Bangladesh Maternal Health Voucher Program......................................................... 3

2.0 UGANDA MATERNAL HEALTH VOUCHER PROGRAM …............................................

3.0 EVALUATION OF THE IMPACT OF THE UGANDA PROGRAM...................................

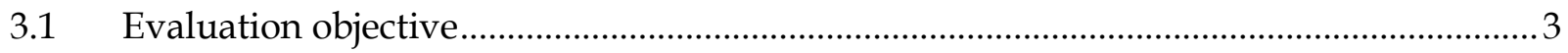

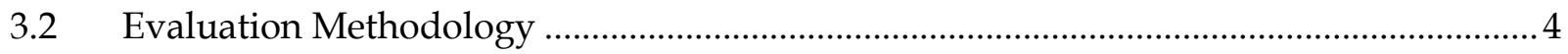

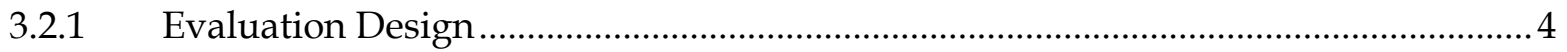

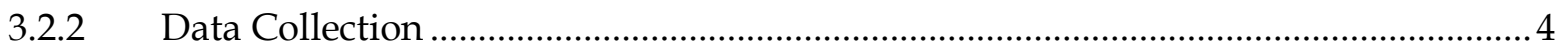

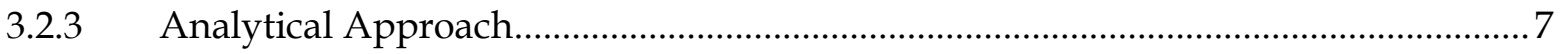

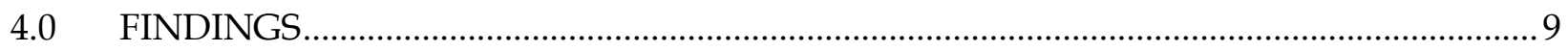

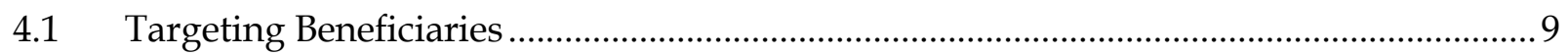

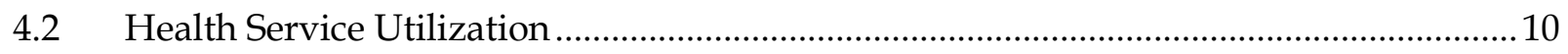

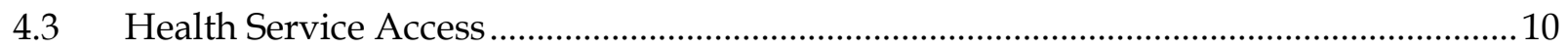

$4.4 \quad$ Local Population Out-of-Pocket Expenditure ............................................................. 11 


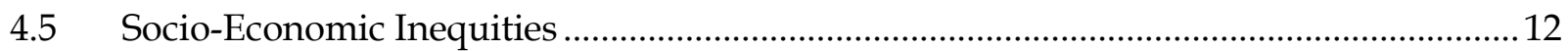

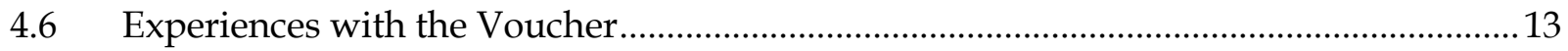

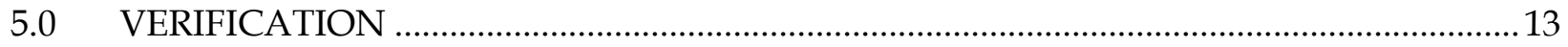

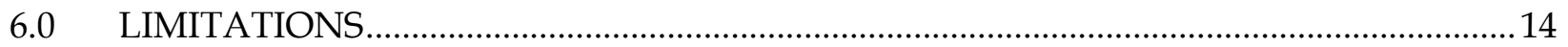

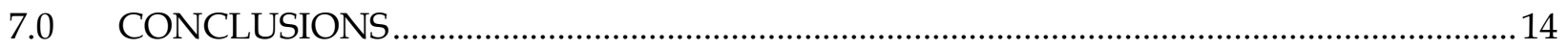

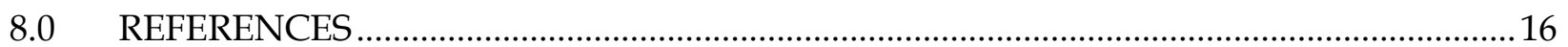




\section{ACRONYMS}

CPDBMS Claims Processing Database Management System

DSF Demand-side Financing

GPOBA Global Partnership on Output-based Aid

GPS Global Positioning System

HIV Human Immunodeficiency Syndrome

KfW Kreditanstalt für Wiederaufbau (German Development Bank)

$\mathrm{MOH} \quad$ Ministry of Health

MSI-U Marie Stopes International- Uganda

OBA Output-based Aid

PWC PricewaterhouseCoopers

STI Sexually Transmitted Infections

UBOS Uganda Bureau of Statistics

UGSh Uganda Shilling

V\&A Voucher and Accreditation

VHSD Venture Strategies for Health and Development

VMA Voucher Management Agency 


\section{EXECUTIVE SUMMARY}

The maternal health voucher program in Uganda was launched in late 2008 with funding from the German Development Bank (KfW) and the Global Partnership on Output-based Aid (GPOBA-World Bank) with GPOBA subsidizing 97\% of the vouchers. The program is being implemented in 20 districts in southwestern part of the country. This report is based on the evaluation of the population-level impact of the program with specific focus on targeting of beneficiaries, health service utilization, out-of-pocket expenses, and equity. It is further based on reviews of the findings from an independent verification of the program that was conducted by PricewaterhouseCoopers (PWC) Limited in 2010. The major findings of the evaluation are that:

- Based on household wealth index, a significantly higher proportion of women from the two poorest quintiles had used the vouchers compared to those from middle, richer and richest quintiles.

- The program significantly contributed to increased deliveries in private facilities, which were accompanied by significant reductions in public facility deliveries as well as in home-based births among voucher compared to non-voucher clients.

- The program was large enough that it significantly contributed to population-level reductions in the proportion of out-of-pocket payments for deliveries in private facilities in the communities exposed to it compared to non-exposed communities.

- $\quad$ There were, however, no significant reductions in health service utilization gap between poor and non-poor women from voucher-exposed communities compared to those from control communities.

- Most of the women who had ever used the voucher indicated that they would recommend its use to a friend mainly because it caters for free, cheap or affordable services; it is good for or helps poor pregnant women access relevant services; and that it enables one to receive good, quality or fast service.

- Although the program made progress in achieving the targeted outputs, there were challenges with respect to regular training of providers, the quality of services in some facilities, compliance with the frequency and format of reporting by facilities, and the administration of the claims processing database management system audit trails. 


\section{BACKGROUND}

\subsection{Introduction}

The combined use of vouchers and output-based contracting is known by several terms: outputbased aid (OBA), demand-side finance (DSF), and voucher and accreditation (V\&A) programs (Gorter et al. 2003; Janisch and Potts 2005; Sandiford et al. 2002). In traditional salaried positions in the health sector, staff may have little incentive to raise their productivity or to be concerned with client perceptions of health care quality. OBA subsidies, however, create incentives to improve the efficiency of healthcare subsidies and increase access for new users of important health services. Vouchers stimulate client demand for healthcare and give the client the purchasing power to seek care from the full range of available providers. Voucher programs have the potential to improve healthcare and health outcomes at the facility level and in the general population. Improvements are grouped into five broad categories of measures, namely, knowledge, behavior (including utilization and access), quality, costs, and disease status (prevalence, incidence, client disease stage).

Knowledge is measured among facility clients, healthcare providers, and general population. Common metrics include knowledge of disease signs, program characteristics (i.e. where to find a voucher or clinic location), and provider recall of treatment guidelines. Improvements in behaviors in the context of a health systems intervention largely encompass health-seeking behaviors. There may be other barriers to care, such as distance, which would keep clients from seeking care. However, if cost is the principal barrier for the poor to use the service, and vouchers are then distributed, then there should be an increase in utilization at facilities. If the burden of untreated disease is high in the general population, it may be possible to detect a change in the utilization patterns of the general population after voucher introduction. Quality is, on the other hand, measured by improvements in facility infrastructure, service delivery process (how clients are treated) and consultation outcomes, for instance, client satisfaction with services as well as reductions in maternal and neonatal morbidity and mortality.

Cost metrics are another important area to monitor in OBA programs. Monitoring client out-ofpocket spending, facility revenue and costs, the ratio of program subsidies to the number of clients serviced, and related expenses give insight into whether the OBA subsidies are effective in improving healthcare delivery and health outcomes. The final area to monitor is population health. Populations can be groups of clients or general populations. Monitoring disease burden can be as complex or simple as dictated by need to determine the impact, however that may be defined. Risk of new disease in a population served by contracted facilities may be one measure. Odds of exposure in clinic-based cases and controls may be another approach. Change in prevalence in a before-and-after design may be yet another metric that indicates to the administrators, funders, and other stakeholders whether OBA subsidies are a success. 


\subsection{Examples of Reproductive Health Voucher Programs}

Several countries have employed the OBA voucher subsidy to deliver health services to lowincome populations.

\subsubsection{Taiwan Voucher Program}

The first use of output-based voucher subsidy for health care in low-income countries was done on a large scale in Taiwan in the 1960s and 1970s. The Taiwan Ministry of Health offered male and female sterilization services at government and private facilities (Cernada and Chow 1969). The system was set up to subsidize the cost for low-income couples, targeting the service to couples with two or more children. The voucher subsidized a routine health service in which all couples seeking sterilization participated, regardless of their income level. Couples that did not qualify for the subsidy purchased their voucher and selected their provider. Low-income couples did not pay the fee but received the same voucher, chose from the same network of providers, and received the same level of care.

\subsubsection{Nicaragua Voucher Program}

After the Taiwan program, there is no record of other voucher subsidy programs until 20 years later when Nicaragua implemented two voucher programs to treat sexually transmitted infections (STIs) in 1995. One program targeted commercial sex workers as a strategy to prevent the spread of HIV. Sandiford and colleagues (2002) noted that the introduction of the sex worker voucher after 1995 was accompanied by annual declines in the prevalence of syphilis $(8.6 \%)$ and gonorrhea $(9.4 \%)$ among the poorest sex workers. The second program targeted adolescents. The adolescent vouchers were used 15,134 times over the same period as the sex worker voucher (Meuwissen et al. 2006). As a result of the program, utilization of reproductive health services, including contraceptives, by adolescents was higher among voucher compared to non-voucher clients (Meuwissen et al. 2006).

\subsubsection{Gujarat Safe Delivery Voucher Program}

The Gujarat safe delivery voucher program, also known as "Chiranjeevi Yojana" or "eternal life scheme", was launched in December 2005 in Gujarat state of India. The objective of the program was to improve health facility delivery by subsidizing access to private medical providers for pregnant women living below the official poverty line in remote areas with the highest infant and maternal mortality. The scheme was launched as a single year pilot project in five districts: Banaskantha, Dahod, Kutch, Panchmahal, and Sabarkantha (Bhat et al. 2009). Voucher holders were provided with a transport stipend and private contracted providers were reimbursed on a capitation payment basis. The payments were made for a batch of 100 deliveries to take care of case-mix differences (i.e., normal or complicated deliveries). The costs for normal and complicated deliveries were based on the prevailing market rates. The program led to increased delivery at private health facilities by voucher clients (Bhat et al. 2009). 


\subsubsection{Bangladesh Maternal Health Voucher Program}

The Bangladesh maternal health voucher scheme started as a pilot program in 21 sub-districts in 2006 and was expanded to 33 sub-districts by 2010 (Ahmed and Khan 2011). Two different targeting mechanisms are used: in 24 of the targeted sub-districts, household asset scoring is used to identify the poor. In the remaining nine sub-districts, all women qualify for the vouchers (universal targeting). The program subsidizes antenatal, delivery, and post-natal care for the first or second pregnancy. The program also covers transport for poor women. Providers are mostly from the public sector but include a few providers from the non-governmental and private-for-profit sectors. Incentives provided through the OBA subsidies motivated providers from the public sector to offer higher level services (Ahmed and Khan 2011).

\subsection{UGANDA MATERNAL HEALTH VOUCHER PROGRAM}

The maternal health voucher program in Uganda was launched in late 2008 with funding from the German Development Bank (KfW) and the Global Partnership on Output-based Aid (GPOBA-World Bank) with GPOBA subsidizing 97\% of the vouchers. The program is being implemented in 20 districts in southwestern part of the country. The voucher, also known as HealthyBaby, costs UGSh. 3,000 (approximately US \$1.40) and subsidizes safe motherhood services (four antenatal care visits, delivery and postnatal care up to six weeks) to economically disadvantaged women. Community-based voucher distributors are responsible for targeting poor pregnant women using district-customized poverty grading tool.

Accredited providers are either private for- or not-for-profit facilities that offer basic or comprehensive emergency obstetric care. Marie Stopes International-Uganda (MSI-U) is the voucher management agency (VMA). Its role is to accredit providers, distribute the vouchers, ensure quality, verify and process claims, and control fraud. Other partners include the Ministry of Health (MOH), Mbarara University of Science and Technology, University of California at Berkeley and Venture Strategies for Health and Development (VSHD).

\subsection{EVALUATION OF THE IMPACT OF THE UGANDA PROGRAM}

\subsection{Evaluation objective}

VSHD undertook a population-based evaluation of the maternal health voucher program in Uganda with funding from GPOBA while the Bill and Melinda Gates Foundation supported the analysis of the data. The purpose of the evaluation was to determine the impact of the voucher program on improving reproductive health behaviors and outcomes at the population level. The specific behaviors and outcomes considered included:

(i) targeting;

(ii) health service utilization and access;

(iii) out-of-pocket expenses;

(iv) equity; and

(v) client experiences with the vouchers. 


\subsection{Evaluation Methodology}

\subsubsection{Evaluation Design}

The evaluation used a before-and-after with controls design over two rounds of populationbased household surveys. The design was informed by the fact that there was no random assignment of sites to the intervention. The original design was for systematic placement of voucher distributors (with random start at one village) in 22 clusters of villages to ensure an even distribution of voucher and non-voucher sites. However, immediately after the baseline survey, there was a period of insufficient communication between the researchers and the program operations team resulted in a deviation from the original plan. The baseline household survey was conducted in 2008 while the follow-up survey was carried out in late 2010 and early 2011. The surveys were conducted in Mbarara, Ibanda, Isingiro, Kiruhura, Kamwenge, and Bushenyi districts where the maternal health voucher program was first started.

Both baseline and follow-up surveys used a two-stage cluster sample design. First, geographic data obtained from the Uganda Bureau of Statistics (UBOS) were used to identify parishes within 5 to 10 kilometers of 13 facilities that were initially contracted to provide services to voucher clients and within three kilometers of a major road. Parishes were then randomly selected from among those within the stipulated distance to the facilities. In the second stage, villages were randomly selected from the sampled parishes. At baseline, 58 parishes were randomly selected for inclusion in the study. There were 231 villages within the parishes with population sizes ranging from 75 to 1803 inhabitants, and totaling 102,260 persons according to the 2002 census. A total of 97 villages were randomly selected for inclusion in the study.

At follow-up, 75 parishes were randomly sampled from which 133 villages were selected for inclusion in the study. Of the sampled villages, 68 had been included in the 2008 survey while 65 were sampled from within five kilometers of the contracted facilities in order to maximize the possibility of getting respondents who had likely used the vouchers. This approach was adopted because the 2010 voucher claims data showed very high concentration of clients around the contracted facilities.

\subsubsection{Data Collection}

The target populations in both baseline and follow-up surveys were women aged between 15-49 years who had a pregnancy or birth during the 12 months before the survey and men of similar age group whose partner was pregnant or gave birth over the same period. Two visits were made to each village. The purpose of the first visit was to seek the cooperation of the local council chair, generate a list of households where a pregnancy or birth occurred in the past 12 months, and take Global Positioning System (GPS) coordinates to ensure that all villages were within the prescribed geographical location. The survey was then administered during the second visit to all women living in the households meeting the inclusion criteria. A total 2,266 women and 177 men participated in the baseline survey while 2,313 women and 582 men participated in the follow-up survey. 
In both surveys, respondents provided information on household assets and amenities, healthrelated household arrangements, food security, household expenditures on goods and services, individual background characteristics (age, education level, religious affiliation, and marital and employment status), general health status and health care utilization, childbearing experiences and intentions, family planning knowledge and use, trust and social cohesion in the community, and awareness, use and perceptions about vouchers. Men were further asked about their perceptions regarding the importance, timing, and willingness to pay for antenatal, delivery and post-natal care services for their partners. In 2008, women were asked detailed questions about two most recent births including the use of antenatal, delivery and post-natal care services as well as experiences and management of any complications. In the follow-up survey, women provided detailed information on all births in the five years before the survey. Table 1 presents the distribution of participants in the surveys (2008 and follow-up) by various background characteristics.

Written informed consent was obtained from the participants in both surveys. The Institutional Review Boards of the Population Council and Mbarara University granted ethical clearance for the surveys. 


\begin{tabular}{|c|c|c|c|c|}
\hline \multirow[b]{2}{*}{ Characteristics } & \multicolumn{2}{|c|}{2008} & \multicolumn{2}{|c|}{$2010 / 2011$} \\
\hline & $\begin{array}{r}\text { Women } \\
(\%)\end{array}$ & $\begin{array}{r}\text { Men } \\
(\%)\end{array}$ & $\begin{array}{r}\text { Women } \\
(\%)\end{array}$ & $\begin{array}{r}\text { Men } \\
(\%)\end{array}$ \\
\hline \multicolumn{5}{|l|}{ Age (years) } \\
\hline $15-24$ & 45.7 & 12.4 & 48.0 & 8.8 \\
\hline $25-34$ & 41.8 & 44.1 & 41.0 & 52.1 \\
\hline $35-44$ & 11.0 & 31.6 & 10.2 & 28.9 \\
\hline 45 and above & 0.8 & 10.7 & 0.7 & 6.7 \\
\hline Don't know/missing & 0.8 & 1.1 & 0.1 & 3.0 \\
\hline \multicolumn{5}{|l|}{ District } \\
\hline Bushenyi & 21.3 & 9.0 & 52.6 & 0.0 \\
\hline Ibanda & 10.8 & 23.2 & 7.5 & 16.5 \\
\hline Isingiro & 21.1 & 20.3 & 6.6 & 27.8 \\
\hline Kamwenge & 4.6 & 5.7 & 2.4 & 13.9 \\
\hline Kiruhura & 21.9 & 22.0 & 12.1 & 18.0 \\
\hline Mbarara & 19.8 & 18.6 & 18.8 & 21.7 \\
\hline Missing & 0.4 & 1.1 & 0.0 & 2.1 \\
\hline \multicolumn{5}{|l|}{ Highest education level } \\
\hline No/pre-schooling & 16.2 & 5.7 & 11.2 & 7.2 \\
\hline Primary & 64.8 & 63.8 & 65.3 & 63.9 \\
\hline Secondary and above & 18.1 & 28.3 & 23.4 & 25.8 \\
\hline Missing & 0.9 & 2.3 & 0.1 & 3.1 \\
\hline \multicolumn{5}{|l|}{ Current marital status } \\
\hline Never married & 2.8 & 2.8 & 2.7 & 1.6 \\
\hline Married/living together & 92.5 & 94.4 & 94.3 & 94.3 \\
\hline Formerly married $^{\mathrm{a}}$ & 3.5 & 1.1 & 2.5 & 1.6 \\
\hline Missing & 1.2 & 1.7 & 0.5 & 2.6 \\
\hline \multicolumn{5}{|l|}{ Religious affiliation } \\
\hline Protestant & 43.1 & 40.7 & 50.4 & 44.9 \\
\hline Catholic & 41.0 & 40.7 & 41.5 & 41.2 \\
\hline Muslim & 9.6 & 9.6 & 7.8 & 11.3 \\
\hline Other/no religion & 5.2 & 6.8 & 0.3 & 2.6 \\
\hline Missing & 1.2 & 2.3 & 0.0 & 0.0 \\
\hline \multicolumn{5}{|l|}{ Household wealth index } \\
\hline Poorest & 20.0 & 19.8 & 20.8 & 12.0 \\
\hline Poorer & 20.0 & 19.8 & 19.1 & 22.7 \\
\hline Middle & 20.0 & 20.3 & 19.4 & 25.3 \\
\hline Richer & 20.0 & 19.8 & 20.1 & 18.2 \\
\hline Richest & 20.0 & 20.3 & 20.5 & 21.8 \\
\hline Number of respondents & 2,266 & 177 & 2,313 & 582 \\
\hline $\begin{array}{ll}\text { Notes: } & \begin{array}{l}\text { aFormerly married refers } t \\
\text { rounding. }\end{array} \\
\end{array}$ & rorced & Perce & not sum & \\
\hline
\end{tabular}




\subsubsection{Analytical Approach}

In order to determine the impact of the program, there is need to know the counterfactual, that is, what the outcome would be in the absence of OBA voucher subsidies for comparison with the outcomes in the presence of the interventions (Lopez-Acevedo and Tan 2010). As already noted, the initial design that was aimed at creating the counterfactual-villages randomly assigned to voucher distributors-could not be implemented as planned. The analytical approach therefore involves post-hoc definition of the counterfactual. Two definitions are used: (i) respondents in the 2010-2011 survey who had never used the maternal health voucher (nonvoucher clients), and (ii) among villages that were included in both baseline and follow-up surveys, those where a voucher client was not present in 2010-2011. Women who had ever used the voucher and villages with a voucher client at follow-up therefore represent the intervention groups.

The outcomes of interest include targeting of beneficiaries, health service access and utilization (new use of and general use of antenatal care, health facility delivery and postnatal care services), out-of-pocket expenses, and socio-economic inequities in service utilization. Analysis of targeting of beneficiaries entails cross-tabulation of the indicator of whether the respondent had ever used the maternal health voucher by household wealth index among women who participated in the 2010-2011 survey. Proper targeting should ideally result in only the poor benefitting from the program while utilization by women from richer quintiles would suggest voucher leakage to non-poor. At the very least, it should be expected that more poor compared to non-poor women benefit from the program especially in cases where it is not possible to ensure watertight control of voucher leakage to the non-poor.

Analysis of health service utilization is, on the other hand, based on birth in the five years before the 2010-2011 survey. It considers health service utilization for births occurring before and after the voucher program started among voucher clients (women who had ever used the maternal health voucher) and non-voucher clients. The impact of the program on health service utilization is determined by the difference-in-differences estimate, that is, the difference in changes over time between voucher and non-voucher clients (Gertler et al. 2011). The expectation is that there should be greater increases in health service utilization among voucher compared to non-voucher clients over time. The difference-in-differences estimate is obtained both from simple comparison of changes in proportions utilizing services as well as estimation of multilevel random-intercept logit models due to the hierarchical nature of the data. The multilevel logit models include an interaction term between the indicator of whether the birth occurred to a voucher or non-voucher client and the period of occurrence (before or after the program started). The models control for maternal age at birth, education level, marital status, place and duration of residence, religious affiliation, poverty status, parity, birth order and sex of child.

The impact of the program on out-of-pocket expenses is examined for the most recent birth before the interview date among women from villages that were included in both the 2008 and 2010-2011 surveys. It involves simple comparison of changes in the proportions paying for delivery as well as estimation of multilevel random-intercept logit models predicting the likelihood of paying for delivery at a private or any (public or private) facility. It is expected 
that there should be greater declines in the proportions of women paying for a private facility delivery among those from villages with a voucher client compared to those from villages with no voucher client at follow-up. The multilevel logit models include interaction terms between the year of survey and whether a voucher client was present in the village at follow-up. The models control for maternal age at birth of the most recent child, level of education, marital status, place and duration of residence, religious affiliation, poverty status, and the number of children ever born (parity).

With respect to equity, the analysis involves examining the gap between poor and non-poor women in terms of utilization of maternal health services in the five years preceding the 20102011 survey in villages with and without a voucher client. The health service utilization indicators considered include: making four or more antenatal care visits, delivering at a private or any (public or private) facility, and receiving postnatal care. The expectation is that there should be less inequity (the gap between poor and non-poor women should be narrower) in villages where a voucher client was present compared to villages with no voucher client. Poverty status is measured by household wealth index with women from the poorest two quintiles being considered poor. Similar to the other outcomes, the impact of the program on reducing inequity is examined by a simple comparison of the difference in the proportions of poor and non-poor women using the services in villages with and without a voucher client as well as estimation of multilevel random-intercept models. The models include an interaction term between the indicators of poverty and whether the village had a voucher client. They further control for similar characteristics to models for health service utilization.

The basic form of the multilevel random-intercept logit model with interaction term is given by Equation [1]:

$$
\log i t\left(\pi_{i j k}\right)=\beta_{0}+\beta_{1} X_{1 i j k}+\beta_{2} X_{2 i j k}+\beta_{3} X_{1 i j k} * X_{2 i j k}+\ldots+X_{i j k} \beta_{i}+\mu_{j k}
$$

where $X_{1}$ is the indicator for the period of birth occurrence, $X_{2}$ is the indicator for exposure to the voucher program, and $X_{i}$ is the vector of the control variables in the model for birth $i$ from village $j$ in parish $k$. The parameter $\beta_{0}$ represents the likelihood of the outcome for non-exposed individuals at baseline, $\beta_{1}$ is the difference in the outcomes for non-exposed individuals over time, $\beta_{2}$ is the difference in outcomes between exposed and non-exposed individuals at baseline, $\beta_{3}$ is the difference in the changes in outcomes between exposed and non-exposed individuals over time i.e. the difference-in-differences estimate, $\beta_{i}$ is the vector of parameters for the control variables in the model, and $\mu_{j k}$ are the unobserved characteristics of individuals from the same village and parish that might be correlated with the outcome. 


\subsection{FINDINGS}

\subsection{Targeting Beneficiaries}

Among women who participated in the 2010-2011 survey, 22\% had ever used the HealthyBaby voucher. Slightly less than one-third of women in the poorest and poorer quintiles had ever used the vouchers. The proportions of women that had ever used the voucher were significantly higher among those from the poorest and poorer wealth quintiles compared to those from the middle, richer and richest quintiles ( $p<0.01$ in all cases; Table 2$)$. More than $15 \%$ of women from each of the three top wealth quintiles had ever used the vouchers.

The distribution of voucher and non-voucher respondents by household wealth index shows that a significantly higher proportion of voucher compared to non-voucher respondents were from the poorest forty percent households ( $52 \%$ compared to $38 \%$; $<<0.01$; Table 3 ).

\begin{tabular}{|c|c|c|c|}
\hline Household wealth index & $\begin{array}{c}\text { Voucher } \\
\text { respondents }\end{array}$ & $\begin{array}{c}\text { Non-voucher } \\
\text { respondents }\end{array}$ & All women \\
\hline Poorest quintile & 28.3 & 18.8 & 20.8 \\
\hline Poorer quintile & 23.3 & 17.9 & 19.1 \\
\hline Middle quintile & 14.5 & 20.8 & 19.4 \\
\hline Richer quintile & 18.1 & 20.7 & 20.1 \\
\hline Richest quintile & 15.7 & 21.9 & 20.5 \\
\hline Number of respondents & 502 & 1,811 & 2,313 \\
\hline
\end{tabular}




\subsection{Health Service Utilization}

The proportion of births to voucher respondents whose mothers made four or more antenatal care visits increased by 15 percentage points after the voucher program started while the proportion of births to non-voucher respondents making the same number of visits increased by seven percentage points over the same period (Table 3). Although the increase was greater among voucher compared to non-voucher respondents, the difference-in-differences estimate from the multilevel logit model was not statistically significant indicating that the increase in the proportions of births to voucher respondents whose mothers made four or more antenatal care visits was not significantly different from that of non-voucher respondents after controlling for maternal and child characteristics.

The proportion of private facility births among women who had ever used the HealthyBaby voucher in the 2010/2011 survey increased from 26\% during the period before the voucher program to $52 \%$ after the program began, representing an increase of 26 percentage points. Although an increase in private facility births also occurred among women who had never used the voucher, it was modest, from $18 \%$ before to $28 \%$ after the program began representing an increase of 10 percentage points. The increase in private facility births were significantly greater (by 2.2 times) among voucher compared to non-voucher clients $(\mathrm{p}<0.01$; Table 3$)$.

Table 3: Percentage of births to voucher and non-voucher respondents by use of maternal health services and difference-in-differences estimates in changes over time between voucher and non-voucher clients, 2010-2011

\begin{tabular}{|c|c|c|c|c|c|c|}
\hline \multirow[b]{2}{*}{$\begin{array}{l}\text { Indicator of health } \\
\text { service utilization }\end{array}$} & \multicolumn{2}{|c|}{$\begin{array}{c}\text { Voucher } \\
\text { respondents }(\%)\end{array}$} & \multicolumn{2}{|c|}{$\begin{array}{c}\text { Non-voucher } \\
\text { respondents (\%) }\end{array}$} & \multicolumn{2}{|c|}{$\begin{array}{l}\text { Difference-in- } \\
\text { differences }\end{array}$} \\
\hline & $\begin{array}{l}\text { Before } \\
\text { program }\end{array}$ & $\begin{array}{c}\text { After } \\
\text { program }\end{array}$ & $\begin{array}{l}\text { Before } \\
\text { program }\end{array}$ & $\begin{array}{c}\text { After } \\
\text { program }\end{array}$ & $\begin{array}{l}\text { Percentage } \\
\text { pointsa }^{\mathrm{a}}\end{array}$ & $\begin{array}{c}\text { Odds } \\
\text { ratios }^{b}\end{array}$ \\
\hline $\begin{array}{l}\text { Four or more antenatal } \\
\text { care visits }\end{array}$ & $\begin{array}{c}55 \% \\
(\mathrm{~N}=183)\end{array}$ & $\begin{array}{c}70 \% \\
(\mathrm{~N}=459)\end{array}$ & $\begin{array}{c}49 \% \\
(\mathrm{~N}=779)\end{array}$ & $\begin{array}{c}56 \% \\
(\mathrm{~N}=1281)\end{array}$ & 8 & $\begin{array}{c}1.4 \\
{[0.9-2.2]}\end{array}$ \\
\hline Place of delivery & $(\mathrm{N}=175)$ & $(\mathrm{N}=434)$ & $(\mathrm{N}=708)$ & $(\mathrm{N}=1184)$ & & \\
\hline Home & $30 \%$ & $17 \%$ & $38 \%$ & $31 \%$ & 6 & $\begin{array}{c}0.6^{*} \\
{[0.3-0.9]}\end{array}$ \\
\hline Private facility & $26 \%$ & $52 \%$ & $18 \%$ & $28 \%$ & 16 & $\begin{array}{c}2.2^{* *} \\
{[1.3-3.8]}\end{array}$ \\
\hline Public facility & $44 \%$ & $30 \%$ & $43 \%$ & $41 \%$ & 12 & $\begin{array}{c}0.5^{*} \\
{[0.3-0.9]}\end{array}$ \\
\hline Public/private facility & $70 \%$ & $82 \%$ & $61 \%$ & $69 \%$ & 4 & $\begin{array}{c}1.6 \\
{[0.9-2.8]}\end{array}$ \\
\hline Postnatal care services & $\begin{array}{c}60 \% \\
(\mathrm{~N}=183)\end{array}$ & $\begin{array}{c}67 \% \\
(\mathrm{~N}=459)\end{array}$ & $\begin{array}{c}45 \% \\
(\mathrm{~N}=779)\end{array}$ & $\begin{array}{c}53 \% \\
(\mathrm{~N}=1281)\end{array}$ & -1 & $\begin{array}{c}1.1 \\
{[0.7-1.8]}\end{array}$ \\
\hline $\begin{array}{l}\text { aBased on difference } \\
\text { greater in the comp } \\
\text { intervals are in squa }\end{array}$ & in changes & $\begin{array}{l}\text { n proportio } \\
\text { Based on } \mathrm{n} \\
<0.05 ;{ }^{* *} \mathrm{p}<\end{array}$ & $\begin{array}{l}\text { ng health s } \\
\text { vel logit } m\end{array}$ & $\begin{array}{l}\text { vices: negat } \\
\text { els with int }\end{array}$ & $\begin{array}{l}\text { gn means } \\
\text { on terms-- }\end{array}$ & $\begin{array}{l}\text { hange was } \\
\text { confidence }\end{array}$ \\
\hline
\end{tabular}

\subsection{Health Service Access}

Under the voucher program, there was increased access to voucher subsidized facility deliveries, defined as multiparous mothers delivering at facility for the first time using the 
voucher. The proportion of home-based births among voucher clients declined from $30 \%$ before to $17 \%$ after the program began, representing a decline of 13 percentage points (Table 4 ). Similarly, the proportion of public facility births declined from $44 \%$ before to $30 \%$ after the program started, representing a decline of 14 percentage points. In contrast, the decline in home-based and public facility births among non-voucher respondents was modest, from 38\% to $31 \%$ for home-based births (seven percentage point decline) and from $43 \%$ to $41 \%$ for public health facility births (two percentage point decline).

Results from the multilevel logit model show that reductions in public health facility delivery and home-based births were significantly higher among voucher compared to non-voucher respondents (Table 3). The significant increase in private facility births and similar reductions in home-based births among voucher compared to non-voucher respondents are further indications that the program improved access to facility delivery. There was, however, no significant difference in changes in the use of postnatal care services between voucher and nonvoucher respondents.

\subsection{Local Population Out-of-Pocket Expenditure}

Among villages with a voucher client who delivered most recently at a private facility, the proportion of respondents who paid for the services declined by 44 percentage points between 2008 and 2010/2011 (Table 4). In villages with no voucher client at follow-up, the proportion of women that delivered their most recent babies at a private facility and paid for the services declined by only 11 percentage points between 2008 and 2010/2011. The decline in the proportion of women paying for delivery in private facilities was therefore greater in villages with a voucher client compared to villages with no voucher client at follow-up by 33 percentage points. The difference-in-differences estimate from the multilevel logit model shows that the decline was significantly greater in villages with a voucher client compared to villages with no voucher client.

Table 4: Percentage of women who paid for the delivery of the most recent birth and difference-indifferences estimates in changes over time between villages with and without a voucher client at followup, 2008 and 2010-2011

\begin{tabular}{|c|c|c|c|c|c|c|}
\hline \multirow[b]{2}{*}{ Services } & \multicolumn{2}{|c|}{$\begin{array}{l}\text { Voucher client } \\
\text { present in village at } \\
\text { follow-up }\end{array}$} & \multicolumn{2}{|c|}{$\begin{array}{l}\text { Voucher client not } \\
\text { present in village at } \\
\text { follow-up }\end{array}$} & \multicolumn{2}{|c|}{$\begin{array}{c}\text { Difference-in- } \\
\text { differences }\end{array}$} \\
\hline & $\begin{array}{c}2008 \\
(\%)\end{array}$ & $\begin{array}{c}2010 / 2011 \\
(\%)\end{array}$ & $\begin{array}{c}2008 \\
(\%)\end{array}$ & $\begin{array}{c}2010 / 2011 \\
(\%)\end{array}$ & $\begin{array}{l}\text { Percentage } \\
\text { points }^{\mathrm{a}}\end{array}$ & $\begin{array}{c}\text { Odds } \\
\text { ratios }^{\mathrm{b}}\end{array}$ \\
\hline \multicolumn{7}{|l|}{ Paid for delivery at } \\
\hline Private facility & $\begin{array}{c}98 \% \\
(\mathrm{~N}=206)\end{array}$ & $\begin{array}{c}54 \% \\
(\mathrm{~N}=133)\end{array}$ & $\begin{array}{c}97 \% \\
(\mathrm{~N}=112)\end{array}$ & $\begin{array}{c}86 \% \\
(\mathrm{~N}=21)\end{array}$ & 33 & $\begin{array}{c}0.1^{*} \\
{[0.0-0.9]}\end{array}$ \\
\hline Public facility & $\begin{array}{c}30 \% \\
(\mathrm{~N}=327)\end{array}$ & $\begin{array}{c}25 \% \\
(\mathrm{~N}=149)\end{array}$ & $\begin{array}{c}24 \% \\
(\mathrm{~N}=180)\end{array}$ & $\begin{array}{c}13 \% \\
(\mathrm{~N}=60)\end{array}$ & -6 & $\begin{array}{c}2.2 \\
{[0.7-6.9]}\end{array}$ \\
\hline Public/private facility & $\begin{array}{c}56 \% \\
(\mathrm{~N}=533)\end{array}$ & $\begin{array}{c}39 \% \\
(\mathrm{~N}=282)\end{array}$ & $\begin{array}{c}52 \% \\
(\mathrm{~N}=292)\end{array}$ & $\begin{array}{c}32 \% \\
(\mathrm{~N}=81)\end{array}$ & -3 & $\begin{array}{c}0.9 \\
{[0.4-2.1]}\end{array}$ \\
\hline
\end{tabular}

Notes: aBased on differences in changes in proportions that paid for delivery services: negative sign means the change was greater in the comparison group; bBased on multilevel logit models with interaction terms--95\% confidence intervals are in square brackets; ${ }^{*} \mathrm{p}<0.05$. 
The proportion of women that paid for delivery of the most recent birth in public or private facility declined by 17 percentage points in villages with a voucher client and by 20 percentage points in villages with no voucher client at follow-up between 2008 and 2010-2011 (Table 4). The difference-in-differences estimate from the multilevel logit model was not statistically significant.

\subsection{Socio-Economic Inequities}

There was an 11 percentage-point difference between births to poor and non-poor women whose mothers made four or more antenatal care visits in villages with a voucher client at follow-up (Table 5). In villages with no voucher client, there was a 15 percentage-point difference between births to poor and non-poor women whose mothers made similar number of visits. Although there was a greater gap in making four or more antenatal care visits between poor and non-poor women in villages without a voucher client compared to villages with such a client, the difference-in-differences estimate from the multilevel logit model was not statistically significant.

The results further show that the proportion of births to poor women that were delivered at a private facility was greater in villages with a voucher client compared to villages with no voucher client (Table 5). Nonetheless, the difference in the proportion of births delivered at a private facility between poor and non-poor women was greater by seven percentage points in villages with a voucher client compared to villages with no voucher client. The difference-indifferences estimate from the multilevel logit model was, however, not statistically significant. A similar pattern is noted for births whose mothers received postnatal care services.

\begin{tabular}{|c|c|c|c|c|c|c|}
\hline \multirow[b]{2}{*}{ Services } & \multicolumn{2}{|c|}{$\begin{array}{l}\text { Voucher client } \\
\text { present in village at } \\
\text { follow-up }\end{array}$} & \multicolumn{2}{|c|}{$\begin{array}{l}\text { Voucher client not } \\
\text { present in village at } \\
\text { follow-up }\end{array}$} & \multicolumn{2}{|c|}{$\begin{array}{l}\text { Difference-in- } \\
\text { differences }\end{array}$} \\
\hline & $\begin{array}{c}\text { Poor } \\
(\%)\end{array}$ & $\begin{array}{c}\text { Non-poor } \\
(\%)\end{array}$ & $\begin{array}{c}\text { Poor } \\
(\%)\end{array}$ & $\begin{array}{c}\text { Non-poor } \\
(\%)\end{array}$ & $\begin{array}{l}\text { Percentage } \\
\text { points }^{\mathrm{a}}\end{array}$ & $\begin{array}{c}\text { Odds } \\
\text { ratios }^{b}\end{array}$ \\
\hline $\begin{array}{l}\text { Four or more antenatal } \\
\text { care visits }\end{array}$ & $\begin{array}{c}51 \% \\
(\mathrm{~N}=397)\end{array}$ & $\begin{array}{c}62 \% \\
(\mathrm{~N}=573)\end{array}$ & $\begin{array}{c}37 \% \\
(\mathrm{~N}=82)\end{array}$ & $\begin{array}{c}52 \% \\
(\mathrm{~N}=216)\end{array}$ & -4 & $\begin{array}{c}1.1 \\
{[0.6-2.3]}\end{array}$ \\
\hline Place of delivery & $(\mathrm{N}=364)$ & $(\mathrm{N}=517)$ & $(\mathrm{N}=80)$ & $(\mathrm{N}=198)$ & & \\
\hline Private facility & $25 \%$ & $35 \%$ & $13 \%$ & $16 \%$ & 7 & $\begin{array}{c}0.8 \\
{[0.3-2.1]}\end{array}$ \\
\hline Public facility & $31 \%$ & $35 \%$ & $32 \%$ & $48 \%$ & -12 & $\begin{array}{c}1.5 \\
{[0.7-3.3]}\end{array}$ \\
\hline Public/private facility & $59 \%$ & $74 \%$ & $45 \%$ & $69 \%$ & -9 & $\begin{array}{c}0.9 \\
{[0.5-2.0]}\end{array}$ \\
\hline Postnatal care & $\begin{array}{c}45 \% \\
(\mathrm{~N}=397)\end{array}$ & $\begin{array}{c}59 \% \\
(\mathrm{~N}=573)\end{array}$ & $\begin{array}{c}51 \% \\
(\mathrm{~N}=82)\end{array}$ & $\begin{array}{c}52 \% \\
(\mathrm{~N}=216)\end{array}$ & 13 & $\begin{array}{c}0.5 \\
{[0.3-1.1]}\end{array}$ \\
\hline \multicolumn{7}{|c|}{$\begin{array}{l}\text { Notes: aBased on differences in the proportions of poor and non-poor women that used the health services in } \\
\text { villages with and without a voucher client: negative sign means the difference between the poor and non- } \\
\text { poor was greater in the comparison group; bBased on multilevel logit models with interaction terms--95\% } \\
\text { confidence intervals are in square brackets; }{ }^{*} p<0.05 \text {. }\end{array}$} \\
\hline
\end{tabular}




\subsection{Experiences with the Voucher}

Nearly all (98\%) women who had ever used the HealthyBaby voucher in the 2010/2011 survey indicated that they would recommend its use to a friend. The most commonly cited reasons for willingness to recommend the use of the voucher to a friend were that: (i) it caters for free, cheap or affordable services, (ii) it is good for or helps poor pregnant women access relevant services, and (iii) it enables one to receive good, quality or fast service (Figure 1). Among the two percent who indicated that they would not recommend the use of a voucher to a friend, the major reasons were poor quality services including rude, untrained or uncaring providers, lack of drugs and unavailability of some services, double payment for services, and distance to accredited facility.

Figure 1: Distribution of respondents who would recommend the use of the HealthBaby voucher to a friend by the major reasons

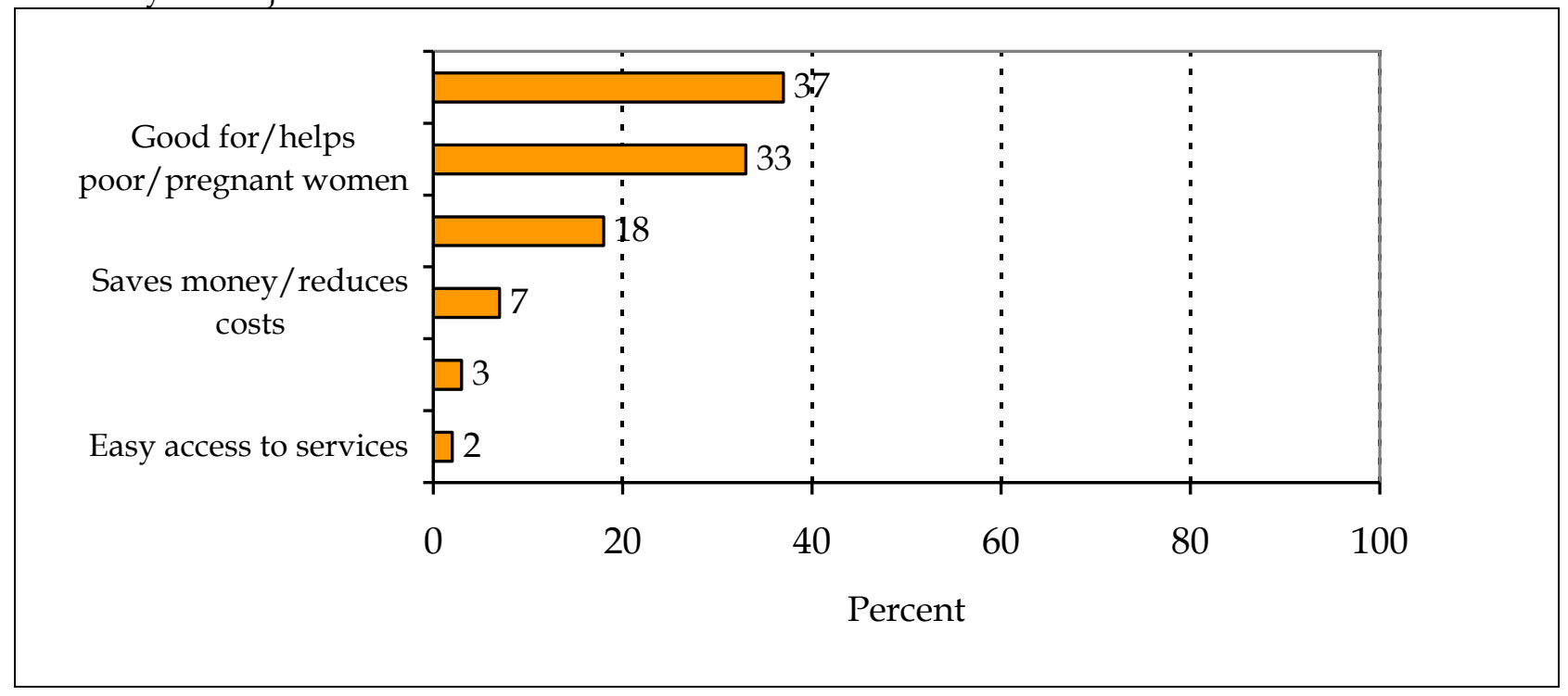

\subsection{VERIFICATION}

KfW contracted PricewaterhouseCoopers (PWC) Limited in June 2010 to conduct an independent verification of the voucher program in Uganda. The objective was to verify the reported outputs of the VMA including the contracted voucher service providers (VSPs), processes and fraud control measures, vouchers sold, and submitted claims. The verification covered the period up to the end of December 2010. A total of 88 health facilities were in the program at the time. It was found that the program had made significant progress towards achieving the output targets of 60,000 safe deliveries by having subsidized a total of 56,412 deliveries (PWC, n.d.). However, the program still faced a number of challenges including:

(i) lack of regular clinical refresher and continuing medical education training;

(ii) inadequate capacity of some health facilities to provide quality services; 
(iii) non-compliance by some facilities regarding the frequency and format of monthly reporting; and

(iv) absence of documented review of the claims processing database management system (CPDBMS) audit trails, regular back-ups, and user access rights leading to staff conflicts in segregation of duties.

\subsection{LIMITATIONS}

1) The temporary lack of communication between the researchers and the program operations team in 2009 after the baseline survey and during the initial implication resulted in a deviation from the original evaluation design. The original design was aimed at creating an even distribution of voucher and non-voucher sites for purposes of determining the impact of the program on reproductive health behaviors and outcomes. The definition of the counterfactual adopted in the present analysis is therefore post-hoc. This could result in over- or under-estimation of the impact of the program. For instance, non-voucher clients as defined in the present report could still have been reached by the program through messages or speaking to a distributor, but decided not to take up a voucher thereby resulting in under-estimation of the program's impact.

2) Another limitation stems from the measure of poverty used, that is, household wealth index rather than the actual criterion used by the voucher management agency to identify beneficiaries. Given the imperfect overlap in measurement, the household wealth index could either include or exclude women who would have qualified based on the poverty grading tool used to identify beneficiaries. However, the poverty grading tool was not administered to survey respondents which could aid in determining the extent to which the two measures overlap.

3) A third limitation is the difficulty in generalizing the results to other populations in Uganda that are farther from contracted health centers. Given the study sampling frame, it was not possible to determine, for instance, the ability of the voucher program to draw in new users from remote and underserved areas. Selecting village clusters within $5-10 \mathrm{~km}$ of the facility ensured high a number of exposed respondents, but as is evident from the proportions of births delivered at a health facility at baseline, many women from these areas were already delivering at facilities prior to the program.

\subsection{CONCLUSIONS}

This report is based on the evaluation of the population-level impact of the maternal health voucher program in Uganda focusing on targeting of beneficiaries, health service utilization (four or more antenatal care visits, facility delivery and postnatal care), out-of-pocket expenses, and equity. It further reviews the findings from an independent verification of the program that was conducted by PricewaterhouseCoopers Limited in 2010. The impact of the program on the outcomes considered is determined through a simple comparison of changes in proportions between intervention and comparison groups before and after the program started as well as 
estimation of multilevel random-intercept logit models with interaction terms between the indicators of exposure to the program and period or poverty status. The major findings are as follows:

(i) Based on household wealth index, a significantly higher proportion of women from the two poorest quintiles had used the vouchers compared to those from middle, richer and richest quintiles.

(ii) The program significantly contributed to increased deliveries in private facilities. This was accompanied by significant reductions in public facility and home-based births suggesting that the program not reduced deliveries occurring at home but also shifted births from public facilities.

(iii) The introduction of the voucher program was associated with an accelerated shift from home to facility deliveries compared to non-voucher clients.

(iv) The program was sufficiently large that it significantly contributed to population level reductions in the likelihood of paying out-of-pocket for deliveries in private health facilities. In particular, there were significant reductions between 2008 and 2010-2011 in the likelihood of paying out-of-pocket for private facility births in villages with a voucher client compared to villages with no voucher client.

(v) With respect to socio-economic inequity in health service utilization, the difference-indifferences estimates from the multilevel logit models show that there were no significant differences in changes in the gap between poor and non-poor women with respect to making four or more antenatal care visits, delivering at a private facility or receiving postnatal care among women in villages with a voucher client compared to villages with no voucher client.

(vi) $98 \%$ of the women who had ever used the voucher indicated that they would recommend its use to a friend mainly because it caters for free, cheap or affordable services; it is good for or helps poor pregnant women access relevant services; and that it enables one to receive good, quality or fast service.

(vii) An independent verification of the program by PWC as of end of 2010 found that although it had made progress in achieving the targeted outputs, there were challenges with respect to regular training of providers, the quality of services in some facilities, compliance with the frequency and format of reporting by facilities, and the administration of the claims processing database management system audit trails. 


\subsection{REFERENCES}

Ahmed, Shakil and M. Mahmud Khan. 2011. "A maternal health voucher scheme: What have we learned from the demand-side financing scheme in Bangladesh?" Health Policy and Planning 26(1):25-32.

Bhat, Ramesh, Dileep V. Mavalankar, Prabal V. Singh, and Neelu Singh. 2009. "Maternal healthcare financing: Gujarat's Chiranjeevi Scheme and Its Beneficiaries." Journal of Health, Population and Nutrition 27(2):249-258.

Cernada, G. and L.P. Chow. 1969. “The coupon system in an ongoing family planning program." American Journal of Public Health and the Nation's Health 59(12):2199-2208.

Gertler, Paul J., Sebastian Martinez, Patrick Premand, Laura B. Rawlings, and Christel M. J. Vermeersch. 2011. Impact Evaluation in Practice. Washington, DC: The World Bank, pp. 95-105.

Gorter, Anna, Peter Sandiford, Zillyham Rojas, and Micol Salvetto. 2003. Competitive voucher schemes for health: Background paper. Mexico: ICAS.

Janisch, Claus P. and Malcolm Potts. 2005. "Smart aid- the role of output-based assistance." Lancet 366(9494):1343-1344.

López-Acevedo, Gladys and Hong W. Tan 2010. Impact evaluation of SME programs in Latin America and Caribbean. Washington, DC: World Bank.

Meuwissen, Liesbeth E., Anna C. Gorter, and Andre J.A. Knottnerus. 2006. "Impact of accessible sexual and reproductive health care on poor and underserved adolescents in Managua, Nicaragua: A quasi-experimental intervention study." Journal of Adolescent Health 38(1):56.e156.e9.

PricewaterhouseCoopers (PWC).n.d. Reproductive health vouchers in Western Uganda project. Kampala: PWC.

Sandiford, Peter, Anna Gorter, and Micol Salvetto. 2002. Vouchers for health: Using voucher schemes for output-based aid. Public Policy for the Private Sector. Note No. 243, World Bank. 